\title{
Heat capacities and thermodynamic properties of ammonium and potassium thiocyanates from 5 to $340 \mathrm{~K} \dagger$
}

\author{
CECIL E. VANDERZEE \\ Department of Chemistry, University of Nebraska, Lincoln, \\ Nebraska 68508, U.S.A. \\ and EDGAR F. WESTRUM, Jr. \\ Department of Chemistry, University of Michigan, Ann Arbor, \\ Michigan 48104, U.S.A.
}

(Received 12 December 1969)

\begin{abstract}
The heat capacities of ammonium and potassium thiocyanates were determined by adiabatic calorimetry over the range 5 to $340 \mathrm{~K}$, and associated thermodynamic functions were computed from the results. At $298.15 \mathrm{~K}$, the heat capacities $C_{p} / \mathrm{cal} \mathrm{K}^{-1} \mathrm{~mol}^{-1}$ and entropies $S^{\circ} / \mathrm{cal} \mathrm{K}^{-1} \mathrm{~mol}^{-1}$ are 29.98 and 33.52 for $\mathrm{NH}_{4} \mathrm{SCN}$ and 21.16 and 29.70 for KSCN. In both salts, the heat capacity contribution from libration of the thiocyanate ions may be represented by two Einstein functions up to $250 \mathrm{~K}$. The torsional motion of the ammonium ion increases rapidly above $100 \mathrm{~K}$ and contributes more than $6 \mathrm{cal} \mathrm{K}^{-1}$ to the heat capacity above $250 \mathrm{~K}$. Adjuvant data on potassium thiocyanate solutions lcad to $S^{\circ}-(34.23 \pm 0.3)$

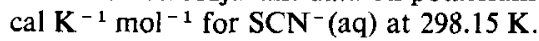

\section{Introduction}

Ammonium halide crystals exhibit transitions in the solid state below $300 \mathrm{~K}$ which are related to the orientation and motion of the ammonium ion. It was of interest to examine the heat capacity of ammonium thiocyanate crystals to establish whether similar behavior occurred for ammonium ions in an environment of rod- or pearshaped anions. Such studies were also made on potassium thiocyanate for comparison of lattice and internal contributions from the thiocyanate ion. A further purpose of this study was to determine the thermodynamic functions for these salts and the entropy of the aqueous thiocyanate ion, as a check on the entropies of $\mathrm{SCN}^{-}(\mathrm{aq})$ and HNCS(g) based on studies by Brandenburg. (1)

\section{Experimental}

\section{CAIORIMETRIC PROCEDURES}

Measurements were made by adiabatic calorimetry at temperatures between 5 and $330 \mathrm{~K}$ for ammonium thiocyanate and between 5 and $350 \mathrm{~K}$ for potassium thiocyanate, using the Mark II cryostat described elsewhere. ${ }^{(2)}$ The automatic adiabatic shield

† This work was supported in part by the Division of Research of the U.S. Atomic Energy Commission. 
control system has also been described previously. ${ }^{2)}$ The gold-plated copper calorimeter used in this study (laboratory designation W-42) has a capacity of $93 \mathrm{~cm}^{3}$ and has horizontal radial vanes for thermal equilibration within the sample. The calorimetric sample of ammonium thiocyanate had a mass of $66.0128 \mathrm{~g}$, and its heat capacity ranged from 91.41 per cent of the total at $16.48 \mathrm{~K}$ to 79 per cent at $103 \mathrm{~K}$ and increased to 84 per cent at $330 \mathrm{~K}$. Buoyancy corrections were based on a density of $1.31 \mathrm{~g} \mathrm{~cm}^{-3}$. Helium at a pressure of 63 Torr at $300 \mathrm{~K}$ was used to facilitate equilibrium in the calorimeter. The calorimetric sample of potassium thiocyanate had a mass of $74.446 \mathrm{~g}$, based on a density of $1.886 \mathrm{~g} \mathrm{~cm}^{-3}$ for buoyancy corrections. It was enclosed with helium gas at a pressure of 75 Torr at $300 \mathrm{~K}$, and its heat capacity ranged from 82 per cent of the total at $10 \mathrm{~K}$ to 75 per cent at $168 \mathrm{~K}$ and increased gradually to 78 per cent at $350 \mathrm{~K}$. A capsule-type strain-free platinum thermometer (laboratory designation A-5) located within the entrant well of the calorimeter was used for temperature measurements. All measurements of mass, temperature, resistance, potential, and time are referred to standardizations and calibrations performed at the National Bureau of Standards.

\section{PREPARATION AND CHARACTERIZATION OF SAMPLES}

Reagent grade ammonium thiocyanate (Baker Analyzed, Lot. No. 34157) was recrystallized once from 50 per cent aqueous methanol and twice from methanol. The solutions were brought to saturation at about $80^{\circ} \mathrm{C}$, then cooled to between 0 and $5{ }^{\circ} \mathrm{C}$. The crystals were recovered in a sintered glass funnel, rinsed with cold methanol, and dried under vacuum over potassium hydroxide pellets. After a preliminary drying, the crystals were broken to uniform size in an agate mortar, dried at $60^{\circ} \mathrm{C}$ for two hours, then held in a vacuum desiccator over potassium hydroxide pellets under high vacuum for ten days. The material was loaded into the calorimeter under conditions of about 48 per cent relative humidity, at which the material is not appreciably hygroscopic. Subsequent evacuation of the calorimeter and flushing with helium was expected to eliminate any traces of water absorbed from the atmosphere during loading. Examination of the heat capacity behavior of the sample near the freezing temperature of methanol indicated 0.05 mass per cent methanol entrapped in the crystals, as calculated from the excess energy absorption $\left(1.2 \mathrm{cal} \mathrm{mol}^{-1}\right.$ ) in Series I (table 1) by attributing the excess to melting of the $\mathrm{CH}_{3} \mathrm{OH}+\mathrm{NH}_{4} \mathrm{SCN}$ eutectic at about $167 \mathrm{~K}$. The excess heat capacity and entropy from this source would be negligible below $160 \mathrm{~K}$, and were estimated at $0.01 \mathrm{cal} \mathrm{K}^{-1} \mathrm{~mol}^{-1}$ from 170 to $273 \mathrm{~K}$, rising to $0.02 \mathrm{cal} \mathrm{K}^{-1}$ $\mathrm{mol}^{-1}$ at $330 \mathrm{~K}$. The estimated excess enthalpy would range from $1.2 \mathrm{cal} \mathrm{mol}^{-1}$ at $170 \mathrm{~K}$ to $2.4 \mathrm{cal} \mathrm{mol}^{-1}$ at $273 \mathrm{~K}$ and to $3 \mathrm{cal} \mathrm{mol}^{-1}$ at $330 \mathrm{~K}$. No adjustment for this effect was made in the tabulated results (tables 1 and 2).

Reagent grade potassium thiocyanate (Baker Analyzed) was recrystallized three times from methanol. The crystals were collected on a sintered-glass filter, rinsed with cold methanol, and given a preliminary drying under vacuum over potassium hydroxide pellets. The crystals were then broken to uniform size in an agate mortar, and dried six hours at 90 to $110^{\circ} \mathrm{C}$. They were subsequently stored under vacuum over potassium hydroxide pellets. Calorimeter loading conditions and procedures were the same as 
THERMODYNAMICS OF AMMONIUM AND POTASSIUM THIOCYANATES 419

for the ammonium thiocyanate. Examination of the heat capacity behavior of the sample near the freezing temperature of methanol showed no detectable amount (less than 0.003 per cent) of methanol entrapped in the crystals.

TABLE 1. Experimental heat capacity of ammonium thiocyanate and potassium thiocyanate

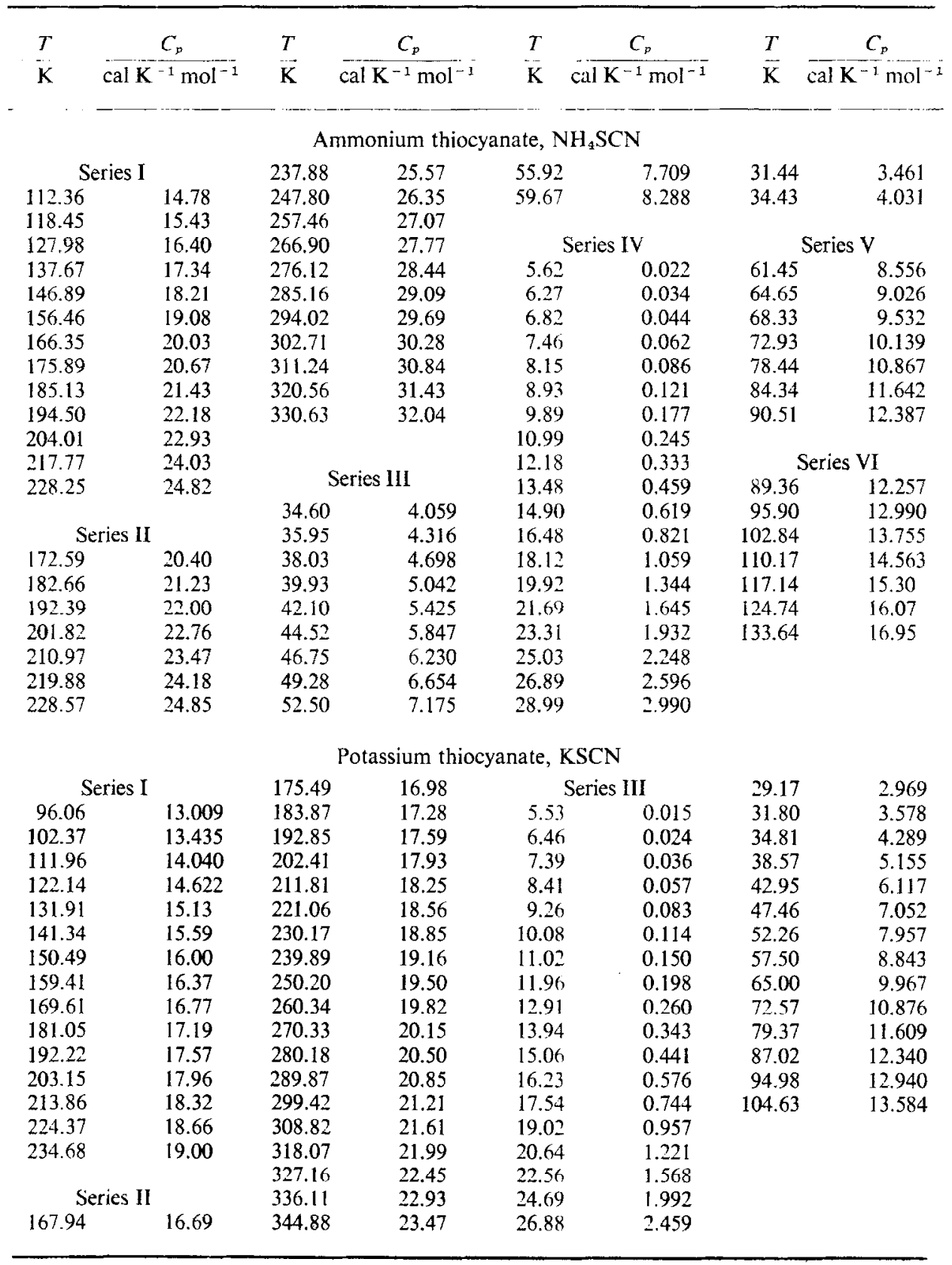




\section{Results}

\section{THERMODYNAMIC PROPERTIES}

The experimental heat capacities at the mean temperature of each determination are listed in chronological order in table 1 and are displayed in figure 1 . These results have been adjusted for curvature and are considered to have a probable error of about

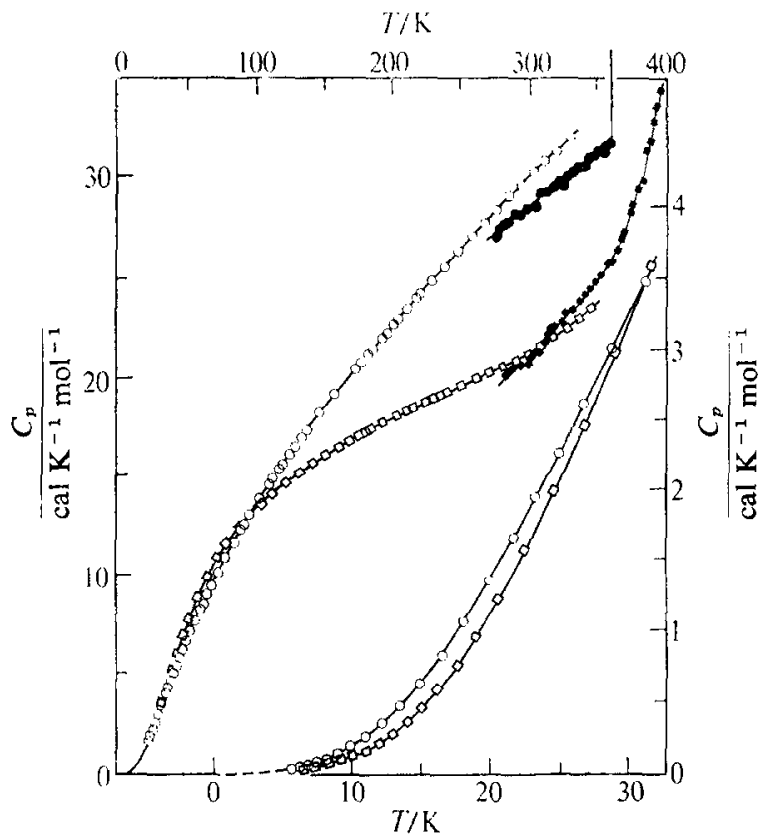

FIGURE 1. Heat capacity behavior of ammonium and potassium thiocyanates. Open circles represent experimental determinations of this research on $\mathrm{NH}_{4} \mathrm{SCN}$; open squares, those on $\mathrm{KSCN}$. The solid circles are unpublished results of $\mathrm{Seki}^{(18)}$ on $\mathrm{NH}_{4} \mathrm{SCN}$ and the solid squares are the results of Sakiyama, Suga, and Seki on KSCN.(15) More recent measurements by Seki ${ }^{(34)}$ are in much closer agreement with ours.

5 per cent at $5 \mathrm{~K}$, decreasing to 1.0 per cent at $10 \mathrm{~K}$ and to less than 0.1 per cent above $20 \mathrm{~K}$. The values are based upon cal $=4.184 \mathrm{~J}$, an ice temperature of $273.15 \mathrm{~K}$, and molar masses of 76.1204 and $97.1838 \mathrm{~g} \mathrm{~mol}^{-1}$ for ammonium and potassium thiocyanate. The smoothed heat capacities and associated thermodynamic functions presented in table 2 were obtained by digital data processing of the experimental results. The functions have a probable error of less than 0.1 per cent above $50 \mathrm{~K}$. Below $6 \mathrm{~K}$, the heat capacities were extrapolated using the Debye $T^{3}$ limiting law. The entropies and Gibbs functions have not been adjusted for nuclear spin and isotopic mixing contributions, and hence are practical values for use in chemical thermodynamic calculations.

\section{ENTROPY OF AQUEOUS THIOCYANATE ION}

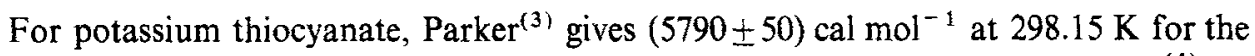
enthalpy of solution, $\Delta H_{\mathrm{s}}^{\circ}$, based on measurements by Partington and Soper. ${ }^{(4)} \mathrm{At}$ 
THERMODYNAMICS OF AMMONIUM AND POTASSIUM THIOCYANATES 421

TABLE 2. Thermodynamic functions of ammonium thiocyanate and potassium thiocyanate

\begin{tabular}{|c|c|c|c|c|}
\hline$T$ & $C_{p}$ & $S$ & $H^{*}-H_{0}^{c}$ & $-\left(G^{r}-H_{0}^{\prime}\right) / T$ \\
\hline $\mathrm{K}$ & cal K $\mathrm{K}^{-1} \mathrm{~mol}^{-1}$ & $\mathrm{cal} \mathrm{K}-1 \mathrm{~mol}^{-1}$ & $\mathrm{cal} \mathrm{mol}-1$ & cal K $\mathrm{K}^{-1} \mathrm{~mol}^{-1}$ \\
\hline \multicolumn{5}{|c|}{ Ammonium thiocyanate } \\
\hline 5 & 0.018 & 0.006 & 0.022 & 0.002 \\
\hline 10 & 0.179 & 0.052 & 0.399 & 0.012 \\
\hline 15 & 0.630 & 0.199 & 2.293 & 0.046 \\
\hline 20 & 1.357 & 0.475 & 7.167 & 0.116 \\
\hline 25 & 2.242 & 0.871 & 16.124 & 0.226 \\
\hline 30 & 3.185 & 1.363 & 29.68 & 0.373 \\
\hline 35 & 4.137 & 1.925 & 47.99 & 0.554 \\
\hline 40 & 5.054 & 2.538 & 70.99 & 0.763 \\
\hline 45 & 5.934 & 3.185 & 98.48 & 0.996 \\
\hline 50 & 6.771 & 3.854 & 130.26 & 1.248 \\
\hline 60 & 8.330 & 5.228 & 205.9 & 1.797 \\
\hline 70 & 9.760 & 6.621 & 296.4 & 2.386 \\
\hline 80 & I1.08I & 8.012 & 400.7 & 3.003 \\
\hline 90 & 12.312 & 9.389 & 517.8 & 3.636 \\
\hline 100 & 13.468 & 10.746 & 646.7 & 4.279 \\
\hline 110 & 14.560 & 12.082 & 786.9 & 4.928 \\
\hline 120 & 15.597 & 13.393 & 937.7 & 5.579 \\
\hline 130 & 16.588 & 14.681 & 1098.7 & 6.230 \\
\hline 140 & .17 .537 & 15.945 & 1269.3 & 6.879 \\
\hline 150 & 18.450 & 17.187 & 1449.3 & 7.525 \\
\hline 160 & 19.33 & 18.406 & 1638 & 8.167 \\
\hline 170 & 20.18 & 19.603 & 1836 & 8.804 \\
\hline 180 & 21.02 & 20.781 & 2042 & 9.437 \\
\hline 190 & 21.83 & 21.939 & 2256 & 10.065 \\
\hline 200 & 22.62 & 23.079 & 2478 & 10.687 \\
\hline 210 & 23.41 & 24.202 & 2709 & 11.304 \\
\hline 220 & 24.19 & 25.309 & 2947 & 11.915 \\
\hline 230 & 24.96 & 26.401 & 3192 & 12.521 \\
\hline 240 & 25.73 & 27.480 & 3446 & 13.122 \\
\hline 250 & 26.49 & 28.545 & 3707 & 13.718 \\
\hline 260 & 27.25 & 29.599 & 3976 & 14.308 \\
\hline 270 & 27.99 & 30.642 & 4252 & 14.894 \\
\hline 280 & 28.72 & 31.673 & 4535 & 15.475 \\
\hline 290 & 29.43 & 32.693 & 4826 & 16.051 \\
\hline 300 & 30.11 & 33.702 & 5124 & 16.623 \\
\hline 310 & 30.76 & 34.70 & 5428 & 17.19 \\
\hline 320 & 31.39 & 35.69 & 5739 & 17.75 \\
\hline 330 & 32.00 & 36.66 & 6056 & 18.31 \\
\hline 273.15 & 28.23 & 30.97 & 4340 & 15.08 \\
\hline 298.15 & 29.98 & 33.52 & 5068 & 16.52 \\
\hline \multicolumn{5}{|c|}{ Potassium thiocyanate } \\
\hline 5 & 0.011 & 0.004 & 0.014 & 0.001 \\
\hline 10 & 0.107 & 0.032 & 0.243 & 0.008 \\
\hline 15 & 0.440 & 0.127 & 1.477 & 0.029 \\
\hline 20 & 1.113 & 0.338 & 5.223 & 0.077 \\
\hline 25 & 2.057 & 0.684 & 13.060 & 0.162 \\
\hline
\end{tabular}


TABLE 2-continued

\begin{tabular}{|c|c|c|c|c|}
\hline $\begin{array}{l}T \\
\overline{\mathbf{K}}\end{array}$ & $\overline{c a l} \frac{C_{\mathrm{n}}}{\mathrm{K}^{-1} \mathrm{~mol}^{-1}}$ & $\frac{S}{\operatorname{cal~K} \mathrm{K}^{-1} \mathrm{~mol}^{-1}}$ & $\frac{H^{\mathrm{c}}-H_{0}^{\circ}}{\mathrm{cal} \mathrm{mol} \mathrm{mol}^{-1}}$ & $\frac{-\left(G^{\circ}-H_{0}^{\mathrm{c}}\right) / T}{\text { cal } \mathrm{K}^{-1} \mathrm{~mol}^{-1}}$ \\
\hline 30 & 3.161 & 1.155 & 26.06 & 0.286 \\
\hline 35 & 4.333 & 1.731 & 44.80 & 0.451 \\
\hline 40 & 5.472 & 2.384 & 69.34 & 0.651 \\
\hline 45 & 6.545 & 3.091 & 99.41 & 0.882 \\
\hline 50 & 7.535 & 3.833 & 134.65 & 1.140 \\
\hline 60 & 9.241 & 5.363 & 218.8 & 1.716 \\
\hline 70 & 10.601 & 6.894 & 318.3 & 2.347 \\
\hline 80 & 11.680 & 8.383 & 429.9 & 3.009 \\
\hline 90 & 12.553 & 9.810 & 551.2 & 3.686 \\
\hline 100 & 13.286 & 11.172 & 680.5 & 4.367 \\
\hline 110 & 13.925 & 12.469 & 816.6 & 5.045 \\
\hline 120 & 14.501 & 13.705 & 958.8 & 5.715 \\
\hline 130 & 15.030 & 14.887 & 1106.5 & 6.376 \\
\hline 140 & 15.519 & 16.019 & 1259.3 & 7.024 \\
\hline 150 & 15.972 & 17.106 & 1416.8 & 7.661 \\
\hline 160 & 16.39 & 18.150 & 1579 & 8.284 \\
\hline 170 & 16.78 & 19.156 & 1745 & 8.894 \\
\hline 180 & 17.15 & 20.126 & 1914 & 9.491 \\
\hline 190 & 17.50 & 21.062 & 2088 & 10.076 \\
\hline 200 & 17.84 & 21.969 & 2264 & 10.648 \\
\hline 210 & 18.18 & 22.848 & 2444 & 11.208 \\
\hline 220 & 18.51 & 23.701 & 2628 & 11.756 \\
\hline 230 & 18.84 & 24.531 & 2815 & 12.294 \\
\hline 240 & 19.17 & 25.340 & 3005 & 12.821 \\
\hline 250 & 19.50 & 26.129 & 3198 & 13.337 \\
\hline 260 & 19.83 & 26.900 & 3395 & 13.844 \\
\hline 270 & 20.16 & 27.655 & 3595 & 14.342 \\
\hline 280 & 20.49 & 28.394 & 3798 & 14.831 \\
\hline 290 & 20.85 & 29.119 & 4004 & 15.311 \\
\hline 300 & 21.23 & 29.832 & 4215 & 15.783 \\
\hline 310 & 21.64 & 30.54 & 4429 & 16.25 \\
\hline 320 & 22.10 & 31.23 & 4648 & 16.70 \\
\hline 330 & 22.60 & 31.92 & 4871 & 17.16 \\
\hline 340 & 23.16 & 32.60 & 5100 & 17.60 \\
\hline 350 & 23.82 & 33.28 & 5335 & 18.04 \\
\hline 273.15 & 20.26 & 27.89 & 3658 & 14.50 \\
\hline 298.15 & 21.16 & 29.70 & 4176 & 15.70 \\
\hline
\end{tabular}

$298.15 \mathrm{~K}$, the solubility in water is $25.08 \mathrm{~mol} \mathrm{~kg}^{-1}$, according to Seidell. (5) Robinson and Stokes ${ }^{(6)}$ recalculated the activity coefficients obtained by Robinson ${ }^{(7)}$ from isopiestic measurements up to $5 \mathrm{~mol} \mathrm{~kg}{ }^{-1}$. Other vapor pressures of $\mathrm{KSCN}$ solutions are those of Pearce and Hopson ${ }^{(8)}$ (up to $10 \mathrm{~mol} \mathrm{~kg}^{-1}$ ) and those of Gibson and Adams ${ }^{(9)}$ (4.59 to $17.328 \mathrm{~mol} \mathrm{~kg}^{-1}$ ). The sets of vapor pressures are consistent with each other in the regions of overlap. The osmotic coefficients from the three sets of data were 
combined on a smooth curve and extrapolated to $25.08 \mathrm{~mol} \mathrm{~kg}^{-1}$, leading to 0.454 for the activity of water at the saturation point. This value agrees with those reported by Korvezee and Dingemans ${ }^{(10)}(0.451,0.46)$ for the activity of water in saturated KSCN solution at $298.15 \mathrm{~K}$, and is consistent with the observation by Kolthoff and Lingane ${ }^{(11)}$ that solid KSCN is deliquescent at 50 per cent relative humidity but is not hygroscopic at relative humidities of 45 per cent or less. Evaluation of the increments in the activity coefficients between Robinson's results and $25.08 \mathrm{~mol} \mathrm{~kg}^{-1}$ involved graphical evaluation of the integral in the relation derived from the Gibbs-Duhem equation:

$$
-\ln \gamma_{\mathrm{s}}=-\ln \gamma_{1}+\left(\phi_{1}-\phi_{\mathrm{s}}\right)+\int_{m_{1}}^{m^{\prime}}(1-\phi) \mathrm{d} \ln m
$$

in which $\phi$ is the osmotic coefficient, $m$ is the molality, and $\gamma_{\mathrm{s}}$ and $\phi_{\mathrm{s}}$ are the values at saturation $\left(25.08 \mathrm{~mol} \mathrm{~kg}^{-1}\right)$. The lower limit of integration $\left(m_{1}, \gamma_{1}, \phi_{1}\right)$ refers to $5 \mathrm{~mol} \mathrm{~kg} \mathrm{k}^{-1}$ and the upper to $m^{\prime}=25.08 \mathrm{~mol} \mathrm{~kg}^{-1}$. We obtained $\gamma_{\mathrm{s}}=0.4465$, $\log _{10} \gamma_{s}=-0.3503$, and estimate \pm 0.005 for the probable error in $\log _{10} \gamma_{s}$ (and also in $\log _{10} m_{\mathrm{s}}$ ). The standard Gibbs energy of solution is then

$$
\Delta G_{\mathrm{s}}^{\circ}=-2 R T \ln \left(m_{\mathrm{s}} \gamma_{\mathrm{s}}\right)=-(1865 \pm 30) \mathrm{cal} \mathrm{mol}^{-1} \text {. }
$$

This combines with $\Delta H_{\mathrm{s}}^{\circ}$ to give $(29.03 \pm 0.23) \mathrm{cal} \mathrm{K}^{-1} \mathrm{~mol}^{-1}$ for $\Delta S_{\mathrm{s}}^{\circ}$, the standard entropy of solution. The entropy of $\mathrm{K}^{+}(\mathrm{aq}),\left(24.50 \mathrm{cal} \mathrm{K}{ }^{-1} \mathrm{~mol}^{-1}\right),{ }^{(12)}$ combined with the entropy of $\mathrm{KSCN}$ from table 4 gives for $\mathrm{SCN}^{-}(\mathrm{aq})$,

$$
S^{\circ}(298.15 \mathrm{~K})=(34.23 \pm 0.3) \mathrm{cal} \mathrm{K}^{-1} \mathrm{~mol}^{-1} \text {. }
$$

NBS Technical Note $270-3^{(12)}$ lists $34.5 \mathrm{cal} \mathrm{K}^{-1} \mathrm{~mol}^{-1}$ for the entropy of $\mathrm{SCN}^{-}$(aq). apparently based on the unpublished measurements by Brandenburg ${ }^{(1)}$ of the enthalpy and Gibbs energy of solution of $\operatorname{HNCS}(\mathrm{g})$ and a statistical calculation of $S^{\circ}$ for HNCS $(\mathrm{g})$. Recent recalculations ${ }^{(13)}$ based on Brandenburg's and statistical data lead to $(34.4 \pm 0.35) \mathrm{cal} \mathrm{K}^{-1} \mathrm{~mol}^{-1}$. The agreement between the two routes to $S^{\circ}$ is excellent, and firmly precludes disorder in the low temperature crystalline form of potassium thiocyanate. The value of $S^{\circ}$ for HNCS(g) is limited in accuracy by the uncertainty in one of the moments of inertia of the molecule and also by the amount of anharmonicity associated with the vibrations.

A similar calculation based on the entropy of $\mathrm{NH}_{4} \mathrm{SCN}$ is not possible for lack of information on the activity coefficients for $\mathrm{NH}_{4} \mathrm{SCN}$ solutions. The calculations can be reversed, however, to yield 0.35 for $\gamma_{5}$ for $\mathrm{NH}_{4} \mathrm{SCN}$ at saturation $\left(23.66 \mathrm{~mol} \mathrm{~kg}^{-1}\right){ }^{(5)}$ This value of $\gamma_{5}$ for $\mathrm{NH}_{4} \mathrm{SCN}$ bears a reasonable relation to that for $\mathrm{KSCN}$, being slightly smaller as usually found for other comparisons of ammonium and potassium salts. ${ }^{(14)}$

\section{Discussion}

\section{IONIC MOTION IN THE THIOCYANATES}

The curves in figure 1 reveal no solid state transitions for either salt in the temperature region studied. Potassium thiocyanate is known to undergo a transition at about $413 \mathrm{~K}$ from orthorhombic to tetragonal symmetry with incrcasing temperature. Seki, ${ }^{(15)}$ Watanabé, ${ }^{(16)}$ and their colleagues present evidence from thermal, spectral, and X-ray studies that this is an order-disorder transition involving the orientation of 
the thiocyanate ion. The transition occurs reversibly without shattering the crystal. Studies by Bridgman (17) showed that the denser low-temperature orthorhombic phase has larger coefficients of thermal expansion and compressibility than the hightemperature phase. Ammonium thiocyanate undergoes transitions at about $361 \mathrm{~K}$ and $392 \mathrm{~K}$. The lower one is a phase transition from monoclinic to orthorhombic symmetry (and higher density) with increasing temperature. The upper transition is apparently an order-disorder transition and involves again orientation of the thiocyanate ions. ${ }^{(18)}$ Bridgman $^{(7)}$ stated that the orthorhombic form of $\mathrm{NH}_{4} \mathrm{SCN}$ is isomorphous with that of $\mathrm{KSCN}$. He also reported that the monoclinic $\mathrm{NH}_{4} \mathrm{SCN}$ has a larger coefficient of thermal expansion but a smaller coefficient of compressibility than orthorhombic $\mathrm{NH}_{4} \mathrm{SCN}$, but gave no actual values for either salt.

Gutowsky and Pake ${ }^{(19)}$ studied nuclear magnetic resonance spectra for several ammonium salts, including $\mathrm{NH}_{4} \mathrm{Cl}, \mathrm{NH}_{4} \mathrm{Br}, \mathrm{NH}_{4} \mathrm{I}$, and $\mathrm{NH}_{4} \mathrm{SCN}$, and found that the line-width changed markedly near $100 \mathrm{~K}$, suggesting significant change in the torsional motion of the ammonium ions well below the temperatures of the phase transitions in the ammonium halides. Richards and Schaefer ${ }^{(20)}$ in more recent $n . m . r$. studies found for $\mathrm{NH}_{4} \mathrm{SCN}$ that the line-width narrows abruptly in going from $72 \mathrm{~K}$ to $90 \mathrm{~K}$. Rush, Taylor, and their colleagues, ${ }^{(21,22)}$ using subthermal neutron scattering to measure the freedom of $\mathrm{NH}_{4}^{+}$ions in a number of salts, conclude that the $\lambda$ transitions in the ammonium salts involve no abrupt change in the torsional frequency or freed om of motion of the $\mathrm{NH}_{4}^{+}$ions. Significant abrupt changes in freedom do occur at the higher temperature first-order transitions, however. We infer that, in ammonium thiocyanate, the ammonium ions gradually increase in rotational freedom beginning at about $70 \mathrm{~K}$ and probably have considerable freedom above $200 \mathrm{~K}$. The neutron scattering studies indicate the potential barrier hindering rotation of the ammonium ion in $\mathrm{NH}_{4} \mathrm{SCN}$ is close to $4 \mathrm{kcal} \mathrm{mol}^{-1}$. $(21,22)$

$X$-Ray studies ${ }^{(16,23-25)}$ on orthorhombic KSCN show four pairs of ions in the unit cell $(a=6.635 \AA, b=6.66 \AA, c=7.58 \AA)$, with the thiocyanate ions at specified orientations in a plane perpendicular to the c-axis and the potassium ions midway between these planes. The monoclinic $\mathrm{NH}_{4} \mathrm{SCN}$ also has four pairs of ions per unit cell $\left(\beta=97.4^{\circ}, a=4.3 \AA, b=7.2 \AA, c=13.0 \AA\right),{ }^{(26)}$ arrayed in a layered structure.

Several infrared and Raman studies have been reported for $\mathrm{KSCN},{ }^{(15,27-29)}$ and also for $\mathrm{NH}_{4} \mathrm{SCN} .^{(18,30,31)}$ These establish quite securely the vibrational frequencies for the $\mathrm{SCN}^{-}$ion in each salt along with those for the $\mathrm{NH}_{4}^{+}$ion. Oden and Decius ${ }^{(30)}$ report torsional wavenumbers of 315,354 , and $375 \mathrm{~cm}^{-1}$ for the $\mathrm{NH}_{4}^{+}$ion. These agree with Tramer's observation ${ }^{(31)}$ (300 to $330 \mathrm{~cm}^{-1}$ ) and are compatible with a rotational barrier of $4 \mathrm{kcal} \mathrm{mol}^{-1}$ for the $\mathrm{NH}_{4}^{+}$ion in $\mathrm{NH}_{4} \mathrm{SCN}$. Savoie and Pézolet ${ }^{(27)}$ showed that the two librational modes of the four $\mathrm{SCN}^{-}$ions in a unit cell would be split into eight components: four in-plane and four out-of-plane librations. Savoie and Pézolet ${ }^{(27)}$ extended the observations by Tramer ${ }^{(28)}$ and report several infrared and Raman lines between 56 and $170 \mathrm{~cm}^{-1}$ for KSCN. A strong band at 69 to $70 \mathrm{~cm}^{-1}$ was attributed to the out-of-plane libration of the $\mathrm{SCN}^{-}$ion, but it is not possible to make unequivocal assignments for the other modes. For $\mathrm{NH}_{4} \mathrm{SCN}$, Tramer ${ }^{(31)}$ observed several wavenumbers between 47 and $190 \mathrm{~cm}^{-1}$, and attributed a broad band at 
47 to $53 \mathrm{~cm}^{-1}$, possibly a doublet, to the out-of-plane libration of the $\mathrm{SCN}^{-}$ion in that salt.

A graphical comparison of the heat capacities of the two salts is given in figure 1. There is little difference between the ammonium and potassium thiocyanate crystals up to about $100 \mathrm{~K}$, but above that temperature the heat capacity of the ammonium salt increases much more rapidly. Most of the difference in heat capacities above $100 \mathrm{~K}$ can be attributed to the rotational heat capacity of the $\mathrm{NH}_{4}^{+}$ion. This observation is fully compatible with the spectral observations cited for the ammonium compound, and is borne out by detailed analyses of the heat capacities of each salt in the following sections.

\section{ANALYSIS OF THE HEAT CAPACITY OF POTASSIUM THIOCYANATE}

The observed heat capacity can be represented as the sum of several contributions, where $C_{\mathrm{vib}}$ arises from internal vibrations of $\mathrm{SCN}^{-}, C_{\mathrm{L}}$ from lattice vibrations, and $C_{\text {lib }}$ from libration of the $\mathrm{SCN}^{-}$ion:

$$
C_{p}=\left(C_{p}-C_{V}\right)+C_{\mathrm{vib}}+C_{\mathrm{L}}+C_{\mathrm{lib}}
$$

For this analysis, the term $\left(C_{p}-C_{V}\right)$ was calculated using the relation

$$
C_{p}-C_{V}=T \bar{V}^{2} / \beta
$$

at $300 \mathrm{~K}$, and from the approximate relation:

$$
C_{p}-C_{V}=A C_{p}^{2} T
$$

at other temperatures. At $300 \mathrm{~K}$, the molar volume $\bar{V}$ is $51.53 \mathrm{~cm}^{3} \mathrm{~mol}^{-1}$, and the value $2.0 \times 10^{-4} \mathrm{~K}^{-1}$ was taken for the coefficient of thermal expansion, $\alpha^{(15)}$ The coefficient of isothermal compressibility, $\beta$, was estimated at $6.6 \times 10^{-6} \mathrm{~atm}^{-1}$, about the same as those for $\mathrm{NH}_{4} \mathrm{Cl}$ and $\mathrm{NH}_{4} \mathrm{Br} .^{(32)}$

The contributions $C_{\mathrm{vib}}$ from internal vibrations of the $\mathrm{SCN}^{-}$ion were calculated from harmonic oscillator (Einstein) functions, using 2053,484, 470, and $748 \mathrm{~cm}^{-1}$ for the wavenumbers..$^{(15,27-29)}$ Upon calculating and subtracting the two preceding contributions from the observed heat capacity, the residue, $\left(C_{V}-C_{\mathrm{yib}}\right)$ or $\left(C_{\mathrm{L}}+C_{\mathrm{lib}}\right)$, could be fitted fairly well by a Debye function for eight degrees of freedom, giving $\Theta_{D}$ ranging from 206 to $217 \mathrm{~K}$ over the region 10 to $170 \mathrm{~K}$.

An alternative and better representation was possible by using a Debye function for six degrees of freedom for the lattice heat capacity, $C_{\mathrm{L}}$, and by representing the librational heat capacity, $C_{\text {lib }}$, as the sum of two Einstein functions, assuming that one wavenumber might, on the average, represent the out-of-plane librations and another the in-plane librations. Over the region 5 to $25 \mathrm{~K}$, values of $\Theta_{\mathrm{D}}$ between 210 and $212 \mathrm{~K}$ together with a librational wavenumber $\tilde{v}^{\prime}$ between 71 and $69 \mathrm{~cm}^{-1}$ gave a satisfactory fit. Using combinations of these parameters, the second librational wavenumber $\tilde{v}^{\prime \prime}$ was selected which best represented the term $\left(C_{\mathrm{L}}+C_{\mathrm{vib}}\right)$ over the region 25 to $200 \mathrm{~K}$. The values selected were: $\beta=6.6 \times 10^{-6} \mathrm{~atm}^{-1}$ (at $300 \mathrm{~K}$ ); $\Theta_{\mathrm{D}}=210 \mathrm{~K}$ (for 6 degrees of freedom); $\tilde{v}^{\prime}=71 \mathrm{~cm}^{-1} ; \tilde{v}^{\prime \prime}=160 \mathrm{~cm}^{-1}$. The lower librational wavenumber $\tilde{v}^{\prime}$ corresponds closely to that identified with the out-of-plane mode. ${ }^{(27,28)}$ The somewhat arbitrary selection of $\beta$ governs the choice of the upper librational wavenumber $\tilde{v}^{\prime \prime}$. Thus increasing $\beta$ to $7.0 \times 10^{-6} \mathrm{~atm}^{-1}$ leads to $212 \mathrm{~K}, 69.5 \mathrm{~cm}^{-1}$, and $153 \mathrm{~cm}^{-1}$ for 
$\Theta_{\mathrm{D}}, \tilde{v}^{\prime}$, and $\tilde{v}^{\prime \prime}$ with an almost equally good fit of the data. The significant result is that the librational heat capacity from the several modes for the unit cell can be represented adequately up to $250 \mathrm{~K}$ by the sum of two Einstein functions, one representing the lower group of frequencies and one the higher group found in the spectra. ${ }^{(27.28)}$

The contributions from the several terms for the selected parameters are shown in figure 2, together with the trend in $\Theta_{\mathrm{D}}$ for the selected values of $\beta, \tilde{v}^{\prime}$, and $\tilde{v}^{\prime \prime}$. Most of the rise in $\Theta_{\mathrm{D}}$ between 200 and $250 \mathrm{~K}$ could be eliminated by

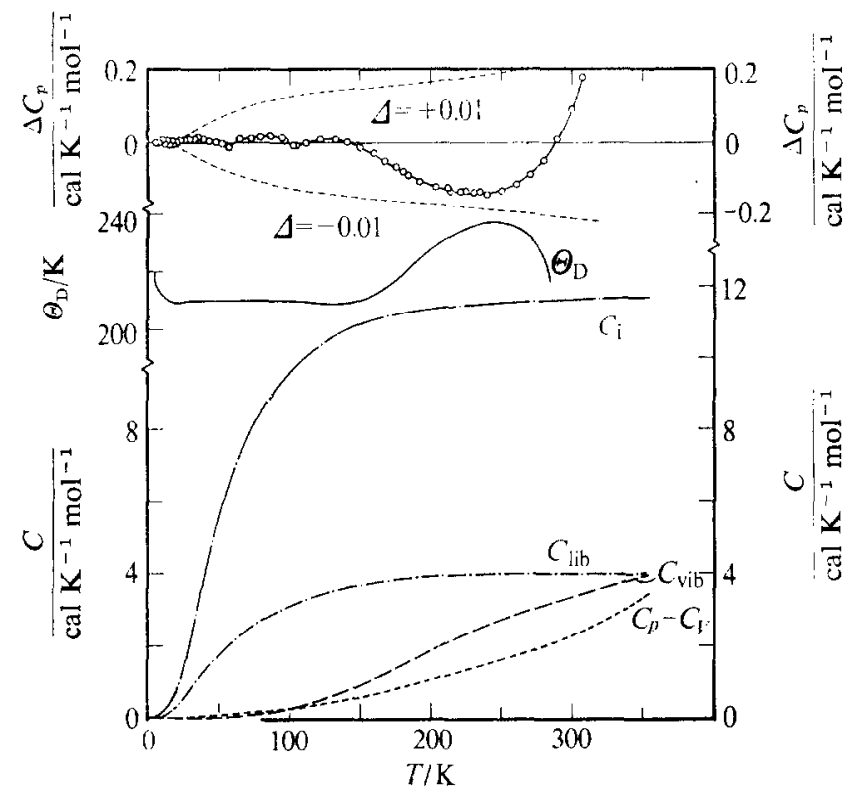

FIGURE 2, Thermal contributions from internal modes in potassium thiocyanate. The contributions calculated as described in the text are indicated at the right of each curve. Open circles represent experimental points. A percentage deviation plot is also depicted to show the quality of fit.

$$
\Delta=\left\{C_{p}(\text { obs. })-C_{p}(\text { calc. })\right\} / C_{p} \text { (obs.) }
$$

making $\beta$ an adjustable parameter with a slightly larger value than that selected. Above $300 \mathrm{~K}$, the difference, $\left\{C_{p}\right.$ (obs.) $\ldots C_{p}$ (calc.) $\}$, strongly indicates the onset of anharmonicity in the librational modes, probably associated with a lowering of the rotational barrier due to expansion of the crystal lattice, and is part of the pre-transitional rise in heat capacity associated with the transition at $413 \mathrm{~K}$.

\section{ANALYSIS OF THE HEAT CAPACITY OF AMMONIUM THIOCYANATE}

For this salt, there is an additional contribution, $C_{\mathrm{r}}$, arising from the torsional vibration (or rotation) of the ammonium ion, together with terms from its internal vibrations. The term $\left(C_{p}-C_{V}\right)$

$$
C_{p}=\left(C_{p}-C_{V}\right)+C_{\mathrm{vib}}+C_{\mathrm{L}}+C_{\mathrm{lib}}+C_{\mathrm{r}}
$$

was evaluated as for KSCN. For $\mathrm{NH}_{4} \mathrm{SCN}$ we used $58.33 \mathrm{~cm}^{3} \mathrm{~mol}^{-1}$ for $\bar{V}, 1.45 \times$ $10^{-4} \mathrm{~K}^{-1}$ for $\alpha^{(18)}$ and $4 \times 10^{-6} \mathrm{~atm}^{-1}$ for $\beta$. In estimating the value for $\beta$, we considered the fact that $\alpha$ for $\mathrm{NH}_{4} \mathrm{SCN}$ was less than that for $\mathrm{KSCN}$, and especially 
considered the observation by Bridgman ${ }^{(17)}$ that the low-temperature monoclinic form of $\mathrm{NH}_{4} \mathrm{SCN}$ has a lower compressibility than the orthorhombic crystals stable above $361 \mathrm{~K}$. The selected value of $\beta$ gives values of $\left(C_{p}-C_{V}\right)$ close to those for KSCN. For the internal vibrations of $\mathrm{NH}_{4}^{+}$, the wavenumbers of Oden and Decius ${ }^{(30)}\left(\tilde{v}_{1}(1)=\right.$ $3070, \tilde{v}_{2}(2)=1677, \tilde{v}_{3}(3)=3138$, and $\left.\tilde{v}_{4}(3)=1425 \mathrm{~cm}^{-1}\right)$ were used. For SCN ${ }^{-}$, the values $\left(\tilde{v}_{1}=2075, \tilde{v}_{2 a}=468, \tilde{v}_{2 a}=482\right.$, and $\left.\tilde{r}_{3}=755 \mathrm{~cm}^{-1}\right)$ represented several sources. ${ }^{18,30,311}$

Up to $100 \mathrm{~K}$, the torsional contribution, $C_{\mathrm{r}}$, from the $\mathrm{NH}_{4}^{+}$ion was approximated by three Einstein functions, using the wavenumbers 315,354 , and $375 \mathrm{~cm}^{-1}$ (at $90 \mathrm{~K}$ ) reported by Oden and Decius. ${ }^{(30)} \mathrm{An}$ equivalent representation below $100 \mathrm{~K}$, but more appropriate above $100 \mathrm{~K}$, was obtained by evaluating the contribution for anharmonic oscillators, ${ }^{(33)}$ based on a potential barrier of $4.2 \mathrm{kcal} \mathrm{mol}^{-1}$ corresponding to a torsional wavenumber of $346 \mathrm{~cm}^{-1} \cdot(21,22)$ Such a calculation can only be a first approximation for a 3-dimensional hindered rotator, but was used to help extend the range of fit for the calculated lattice and librational contributions.

After evaluating and subtracting the preceding terms from $C_{p}$ (obs.), we fitted the residue $\left(C_{\mathrm{L}}+C_{1 \mathrm{ib}}\right)$ to a Debye function for six degrees of freedom and two Einstein functions representing the librations of the $\mathrm{SCN}^{-}$ion. From 15 to $40 \mathrm{~K}$, the data could be represented by $(226 \pm 2) \mathrm{K}$ for $\Theta_{\mathrm{D}}$ and $(51 \pm 2) \mathrm{cm}^{-1}$ for $\tilde{v}^{\prime}$. The value found for $\tilde{v}^{\prime}$ falls very close to that reported by Tramer ${ }^{(3 t)}$ for the out-of-plane libration of thiocyanate ion. From 5 to $12 \mathrm{~K}$, the calculated heat capacities are too low by several per cent, suggesting a low-lying component in the librational frequencies or inadequacy of the Debye model in this region. From 40 to $80 \mathrm{~K}$ the data could be represented by $(230 \pm 2) \mathrm{K}, 51 \mathrm{~cm}^{-1}$, and $240 \mathrm{~cm}^{-1}$ for $\Theta_{\mathrm{D}}, \tilde{v}^{\prime}$, and $\tilde{v}^{\prime \prime}$. The selection of $\tilde{v}^{\prime \prime}$ is uncertain by 30 to $40 \mathrm{~cm}^{-1}$. with $210 \mathrm{~cm}^{-1}$ leading to $238 \mathrm{~K}$ for $\Theta_{\mathrm{D}}$. Tramer ${ }^{(31)}$ reported a possible libration at $190 \mathrm{~cm}^{-1}$. Use of this value for $\tilde{v}^{\prime \prime}$ forces $\Theta_{\mathrm{D}}$ up to $240 \mathrm{~K}$ at 60 to $80 \mathrm{~K}$. Evidently $\Theta_{\mathrm{D}}$ varies considerably with temperature or the contribution from the torsional modes cannot be represented by harmonic oscillator functions even at 60 to $80 \mathrm{~K}$. This latter possibility exists when the rotational barrier has a strong temperature dependence, as occurs for a barrier sensitive to changes in lattice dimensions. The correction represented by equation (5) does not entirely correct for lattice expansion in terms of the Debye model, and the approximations inherent in equation (6) may be even less valid for torsional modes. Oden and Decius ${ }^{(30)}$ found torsional wavenumbers at 315,354 , and $375 \mathrm{~cm}^{-1}$ at $90 \mathrm{~K}$, while at about $295 \mathrm{~K}$ Tramer found the torsional wavenumbers at 300 to $320 \mathrm{~cm}^{-1}$. Similar changes in torsional wavenumbers with temperature have been observed for the ammonium halides. ${ }^{(22)}$ The diminution of barrier height with increase in temperature would accentuate the gain in rotational freedom of the $\mathrm{NH}_{4}^{+}$ion above $100 \mathrm{~K}$ and help account for the large heat capacity contribution as a hindered rotator.

Figure 3 shows the contributions attributed to the several terms, and the trend found for $\Theta_{\mathrm{D}}$, based on $4 \times 10^{-6} \mathrm{~atm}^{-1}$ for the compressibility coefficient $\beta$, and 51 and $240 \mathrm{~cm}^{-1}$ for $\tilde{v}^{\prime}$ and $\tilde{v}^{\prime \prime}$. The contribution $C_{\mathrm{r}}$ from the torsion-rotation of the $\mathrm{NH}_{4}^{+}$ion was estimated from the relation:

$$
\left.C_{p} \text { (obs.) }-\left\{C_{p}-C_{V}+C_{\text {vib }}+C_{\mathrm{L}}+C_{\text {lib }}\right\} \text { (calc. }\right)=C_{\mathrm{r}} .
$$




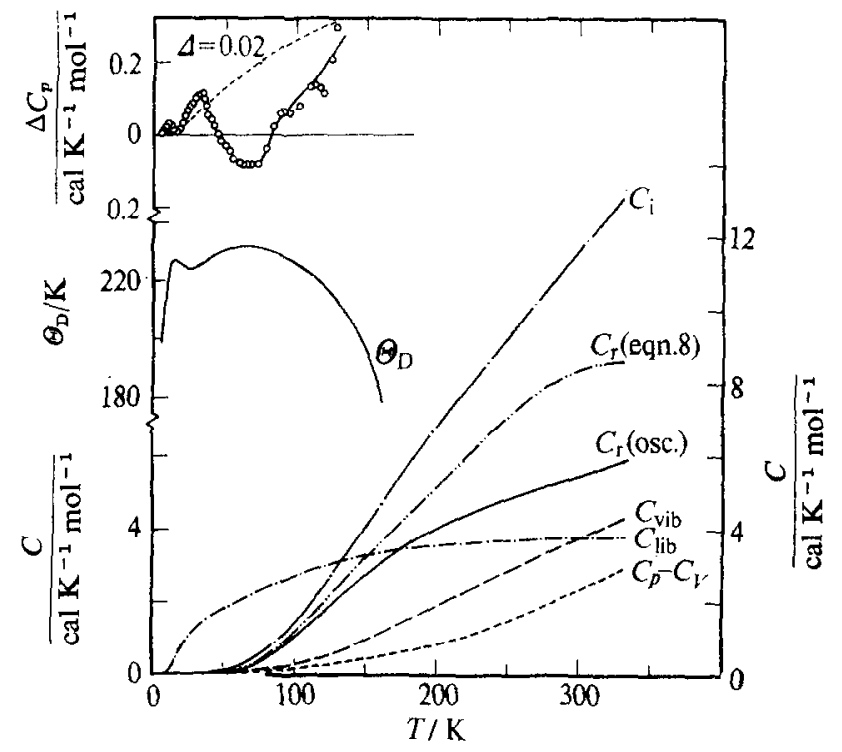

FIGURE 3. Thermal contributions from internal modes in ammonium thiocyanate. The contributions calculated as described in the text are indicated at the right of each curve. A percentage deviation plot is also depicted to show the quality of fit based on equation (7).

$$
\left.\Delta=\left\{C_{\mathfrak{p}} \text { (obs.) }-C_{p} \text { (calc., equation } 7\right)\right\} / C_{p} \text { (obs.). }
$$

Above $250 \mathrm{~K}, C_{1 i b}$ was adjusted for anharmonicity by estimation from $\left\{C_{p}\right.$ (obs.) $C_{p}$ (calc.) $\}$ for $\mathrm{KSCN}$ (previous section). The original selection for $\beta\left(4 \times 10^{-6} \mathrm{~atm}^{-1}\right.$ at $300 \mathrm{~K})$ leads to values of $C_{\mathrm{r}}$ which seem a bit large $\left(8.4 \mathrm{cal} \mathrm{K}^{-1} \mathrm{~mol}^{-1}\right.$ at $300 \mathrm{~K}$ for three degrees of freedom), but which are in good agreement with the adjusted difference between the heat capacities for $\mathrm{NH}_{4} \mathrm{SCN}$ and $\mathrm{KSCN}\left\{\left(C_{p}\left(\mathrm{NH}_{4} \mathrm{SCN}\right)-\right.\right.$ $\left.C_{p}(\mathrm{KSCN})-C_{\mathrm{vib}}\left(\mathrm{NH}_{4}^{+}\right)\right\}$. Increasing $\left(C_{p}-C_{V}\right)$ by 50 per cent (taking $\beta=2.67 \times$ $10^{-6} \mathrm{~atm}^{-1}$ at $300 \mathrm{~K}$ ) gives more reasonable values for $C_{\mathrm{r}}$ but suggests a rather low compressibility for $\mathrm{NH}_{4} \mathrm{SCN}$. Experimental values for $\beta$ as a function of temperature would be highly desirable for more reliable resolution of the problem.

We appreciate the support of the Division of Research of the U.S. Atomic Energy Commission, and the cooperation and stimulating discussions with Dr. Ian McKinnon in this research. One of us (C.E.V.) acknowledges with gratitude the support of the University of Nebraska Research Council for a leave of absence to conduct this research. We are grateful to Professor Syûsô Seki for making some of his results available to us prior to publication.

\section{REFERENCES}

1. Brandenburg, J. T. Ph.D. Thesis, University of Nebraska, 1958.

2. Westrum, E. F., Jr.; Furukawa, G. T.; McCullough, J. P. Experimental Thermodynamics. McCullough, J. P.; Scott, D. W.; editors. Butterworths: London. 1968. 
3. Parker, V. B. Thermal Properties of Aqueous Uni-Univalent Electrolytes. National Standard Reference Data Series-NBS2. U.S. Govt. Printing Office: Washington, D.C. 1965.

4. Partington, J. R.; Soper, W. E. Phil. Mag. 1929, [7] 7, 209.

5. Seidell, A.; Linke, W. F. Solubilities of Inorganic and Metal-Organic Compounds. 4th Ed. Iol. $/ 1$. American Chemical Society: Washington, D.C. 1965.

6. Robinson. R. A.; Stokes, R. H. Trans. Faraday Soc. 1949, 45. 612.

7. Robinson, R. A.J. Amer. Chem. Soc. 1940, 62, 3131.

8. Pearce, J. N.; Hopson, H. J. Phys. Chem. 1937, 41, 535.

9. Gibson, R. E.; Adams, L. H. J. Amer. Chem. Soc. 1933, 55, 2679.

10. Korvezee, Miss A. E.; Dingemans, P. Rec. Trav. Chim. 1943, 62, 625; 1943, 62, 653.

11. Kolthoff, I. M.; Lingane, J. J. J. Amer. Chem. Soc. 1935, 57, 2126.

12. Wagman, D. D.; Evans, W. H.; Parker, V. B.; Halow, I.; Bailey, S. M.; Schumm, R. H. Natl. Bus. Std. Tech. Note 270-3. U.S. Government Printing Office: Washington, D.C. 1968.

13. Vanderzee, $\mathrm{C}$. E. Unpublished calculations.

14. Stokes, R. H.; Robinson, R. A. Electrolyte Solutions, 2nd Ed. Butterworths: London. 1959.

15. Sakiyama, M.; Suga, H.; Seki, S. Bull. Soc. Chent. Japan. 1963, 36, 1025.

16. Yamada, Y.; Watanabé, T. Bull. Soc. Chem. Japan. 1963, 36, 1032.

17. Bridgman, P. W. Proc. Amer. Acad. Arts and Sci. 1915, 51, 55; 1938, 72, 235.

18. Seki, S. Private conmunication (University of Osaka, Japan). March, 1968.

19. Gutowsky, H. S.; Pake, G. E. J. Chem. Phys. 1948, 16. 1164.

20. Richards, R. E.; Schaefer, T. Trans. Faraday Soc. 1961, 57, 210.

21. Rush. J. J.; Taylor, T. I.; Havens, W. W. J. Chem. Phys. 1962, 37, 234.

22. leung. P. S. Taylor, T. I.; Havens, W. W. I. Chem. Phrw. 1968, 48, 4912. See also previous studies cited by these authors.

23. Klug. H. P. Z. Krist. 1933, 84, 214.

24. Büssem, W.: Günther, P.; Tubin, R. Z. Physik. Chem. (Leipzig) 1934, 24B, 1.

25. Zhdanov, G. S.; Zvonkova. Z. V. Usp. Khim. 1953, 22, 3.

26. Zvonkova, Z. V.; Zhdanov, G. S. Zhur. Fiz. Khim. 1949, 23. 1495

27. Savoie, R.; Pézolet, M. Canad. J. Chem. 1967, 45, 1677.

28. Tramer, A. Compt. Rend. 1959, 249, 2531.

29. Jones, L. H. J. Chem. Phys. 1956, 25, 1069; 1958, 28, 1234.

30. Oden, L. L.: Decius, J. C. Spectrochim. Acta 1964, 20, 667.

31. Tramer, A. Compt. Rend. 1959, 249, 2755.

32. Bridgman, P. W. Phys. Rev. 1931, 38, 182

33. Pitzer. K. S. J. Chem. Phys. 1937, 5, 469.

34. Seki. S. Private communication (University of Osaka. Japan). August, 1968. 